\title{
Allelopathic Effects of Aqueous Leaf Extracts from Four Shrub Species on Seed Germination and Initial Growth of Amygdalus pedunculata Pall.
}

\author{
Xiuqing Wang ${ }^{1}{ }^{\circledR}$, Jinxin Wang ${ }^{2,3, *}$, Ruiqi Zhang ${ }^{1}$, You Huang ${ }^{1}$, Shulin Feng ${ }^{1}$, Xu Ma ${ }^{1}$, \\ Yuyu Zhang ${ }^{1}$, Ashim Sikdar ${ }^{2,4}$ and Rana Roy ${ }^{2,4}$ \\ 1 Institute of Soil and Water Conservation, Northwest A\&F University, Yangling 712100, China; \\ wangxiuqing_work@163.com (X.W.); zhangruiqi@nwafu.edu.cn (R.Z.); youhuang572799@163.com (Y.H.); \\ shulin_feng@yahoo.com (S.F.); maxu_xnsbs@163.com (X.M.); GS_yuyuzhang@163.com (Y.Z.) \\ 2 College of Resources and Environment, Northwest A\&F University, Yangling 712100, China; \\ ashimsikdarsau@gmail.com (A.S.); ranaroy.aes@sau.ac.bd (R.R.) \\ 3 Key Laboratory of Plant Nutrition and the Agri-Environment in Northwest China, Ministry of Agriculture, \\ Yangling 712100, China \\ 4 Department of Agroforestry and Environmental Science, Sylhet Agricultural University, Sylhet 3100, \\ Bangladesh \\ * Correspondence: jwang118@nwsuaf.edu.cn; Tel.: +86-029-8708-0055
}

Received: 9 October 2018; Accepted: 14 November 2018; Published: 16 November 2018

\begin{abstract}
This study aimed to screen out the shrub species which can promote the seed germination and seedling growth of Amygdalus pedunculata Pall. and offer insight for ecological environment governance of the coal mines subsidence area in Mu Us Sandy Land, Yulin City of Shaanxi Province. The indoor bioassay method was used to study the aqueous leaf extracts from Amorpha fruticosa Linn., Hedysarum mongolicum Turez., Sabina vulgaris Ant., and Hippophae rhamnoides Linn. under different concentration gradients to examine seed germination, initial growth, and physiological and biochemical of two Amygdalus pedunculata varieties (YY-1 from Yuyang County (YY) and SM-6 from Shenmu County (SM), Shaanxi Province, China). The results showed that with aqueous leaf extracts concentrations at lower concentrations of 0.025 (T1) and $0.05 \mathrm{~g} \cdot \mathrm{mL}^{-1}$ (T2) from A. fruticosa, $H$. mongolicum, and S. vulgaris significantly promoted seed germination and seedling growth of two $A$. pedunculata varieties. Moreover, $H$. rhamnoides aqueous leaf extracts had the strongest inhibitory effect on seed germination and seedling growth of $A$. pedunculata, and death occurred at concentrations of 0.15 (T4) and $0.20 \mathrm{~g} \cdot \mathrm{mL}^{-1}$ (T5). The enzyme activity and chlorophyll content of the A. pedunculata leaves decreased with an increase in the aqueous leaf extracts concentration of the four shrubs; the change trend of malondialdehyde content was the opposite. Root activity of the A. pedunculata increased and then decreased. The H. mongolicum and S. vulgaris are the most suitable mixed tree species for YY-1, while H. mongolicum and A. fruticosa are the most suitable mixed tree species for SM-6 at a relatively low density with more security. The results provide a theoretical basis and technical support for the establishment of an artificial mixed forest of A. pedunculata in the coal mine subsidence area of Mu Us Sandy Land.
\end{abstract}

Keywords: allelopathy; Amygdalus pedunculata; Amorpha fruticosa; Hedysarum mongolicum; Sabina vulgaris; Hippophae rhamnoides; seed germination; initial growth; physiological and biochemical

\section{Introduction}

Amygdalus pedunculata Pall. is a perennial deciduous shrub and one of the most important ecologically economical tree species. It is widely cultivated in the coal mining subsidence area of Mu Us 
Sandy Land. For pure forests of A. pedunculata, influenced by local conditions, seedlings are susceptible to sand burial, and sandy soil itself lacks moisture and nutrients [1]. Forest biodiversity is low, causing slow growth of A. pedunculata [2-4]; thus, it is difficult to realize the shrub's ecological and economic benefits in the short term. At the same time, residents have neglected the management of $A$. pedunculata, so its resource advantages have not been fully realized. Therefore, farmers and local governments are extremely concerned about improving the stand quality of A. pedunculata, improving its ecological and economic benefits, and having better governance over the ecological environment in the coal mining subsidence area of $\mathrm{Mu}$ Us Sandy Land. These issues warrant urgent investigation.

Put simply, a mixed-mode forestry ecological system offers multiple benefits. Many studies have shown that reasonable collocation of mixed tree species increases the diversity of forest communities, effectively improves woodland soil fertility, promotes root growth, and improves nutrient absorption and utilization [5-7]. Collocation can also effectively inhibit weeds and insect pests, enhance trees' photosynthetic capacity, increase soil enzyme activity and microbial diversity, promote tree growth, and enhance forest stand stability [8-11]. These improvements enhance trees' adaptability via mixed transformation, ecosystem restoration, and potentially improved forest productivity [12]. Therefore, in the planting area of $A$. pedunculata, it will be beneficial to introduce suitable native shrub tree species with reciprocal effects to transform pure forests into mixed forests.

The coal mines subsidence area in Yulin of Shaanxi province, China, is located in the southern margin of Mu Us Sandy Land. The main suitable shrub tree species for planting include Amorpha fruticose Linn., Hedysarum mongolicum Turez., Sabina vulgaris Ant., and Hippophae rhamnoides Linn. Among them, A. fruticosa, H. mongolicum, and H. rhamnoides have an outstanding rhizobium symbiotic nitrogen fixation system to effectively improve soil nitrogen and fertility while increasing soil organic matter, thereby improving sandy land [13-15], excluding nutrient competition for A. pedunculata. S. vulgaris is one of the only species of evergreen shrub in the region and plays an irreplaceable role in enhancing the ecological winter landscape [16]. More importantly, four species of shrub have extensive root systems, leading to stronger tolerance to cold, drought, barrenness, salt alkali, and sand burial $[17,18]$; hence, these species can adapt to the environment of sandy areas. The selection leaves of these four species of shrub as associated donor species therefore exhibit a strong typicality and representativeness.

Allelopathy is defined as the beneficial or unfavorable effects of metabolic secretions of plants or microorganisms on other plants or microorganisms in the environment [19]. Moreover, allelopathy more commonly refers to the inhibitory effects of one species on another. However, Ninkovic [20] and Glinwood et al. [21] proposed the term 'allelobiosis' to indicated that the exchange of phytochemicals was informative for receiving plants, and the response of receiving plants affects their growth strategy, and their relationship to herbivores and their natural enemies. They argued that allelopathy and allelobiosis were any chemical-mediated interactions between plants, whether positive or negative. Therefore, allelopathy is widely distributed in ecosystems and plays an important role in species' rational allocation, forest tending, weed control, pest control, and disease prevention and control [22-24].

Seed germination is the primary and inevitable stage of plant survival and reproduction, and the seedling stage is also a relatively fragile stage during plant growth [25]. In these stages, the inhibition or promotion of other plants will affect the seed germination or seedling growth. Many studies have shown that allelochemicals affect the activities of enzymes, malondialdehyde, chlorophyll and root activity in plants, and these physiological and biochemical indicators were important indicators of plant growth.

In nature, the mutual competition of tree species will inevitably lead to competition for sunlight, water, and nutrients. At the same time, compound allelochemicals can inhibit and promote cell membrane permeability, photosynthesis, nutrients and enzyme activities through different release pathways, such as leaching, volatilization, plant residue or litter decomposition, and so on. [19]. 
However, there is a dearth of research on the allelopathic effects between the endemic economic trees species of A. pedunculata and other shrub species in Yulin region. At present, there was no relevant literature which reported on the growth pattern of the chosen companion species for mixing with A. pedunculata, and also no reference to its competitiveness.

If the A. pedunculata seeds are able to germinate normally and grow healthily in the sand area under the allelopathy and allelobiosis, the survival and natural reproduction of tree species can be guaranteed, and the diversity and stability of community structure can be restored. Therefore, in order to screen out the shrub species which can promote the growth of the A. pedunculata, it is necessary to study the effects of these shrub aqueous leaf extracts on the seed germination and seedling growth of the A. pedunculata.

This study may provide a theoretical basis and technological support for the cultivation of an A. pedunculata mixed forest in the coal mine subsidence area of $\mathrm{Mu}$ Us Sandy Land in Yulin City, Shaanxi Province, playing a reciprocal symbiotic role for economic tree species A. pedunculata and associated shrub species to promote ecological environment restoration and enhanced economic benefits.

\section{Materials and Methods}

\subsection{Seed and Plant Material}

Receptors were seeds and seedlings of A. pedunculata (YY-1 from Yuyang County (YY) and SM-6 from Shenmu County (SM), Shaanxi Province, China). The basic layout of seed sampling points is shown in Table 1; the seeds' morphological characteristics appeared in Table 2. The methods were according to Yan et al. [26] and Wang et al. [27]: the thousand weight of seeds and seed kernels were to randomly select 1000 seeds and seed kernels of two A. pedunculata varieties with disease-free pests and full-grain, and weighed them with an electronic balance (FA3104N, Shanghai Jinghai, Shanghai, China), this was repeated 3 times, and then we calculated the average value. The single volume of seed and seed kernel were determined by the volumetric method. Kernel rate was the percentage of seed kernel weight and seed weight.

Table 1. The basic layout of seed sampling points for experimental materials.

\begin{tabular}{ccccccc}
\hline Habitat & Population Code & Longitude (E) & Latitude (N) & Altitude (m) & AMP $^{\mathbf{1}}(\mathbf{m m})$ & AMT $^{2}\left({ }^{\circ} \mathbf{C}\right)$ \\
\hline $\begin{array}{c}\text { Yuyang County, } \\
\text { Shaanxi Province }\end{array}$ & YY & $108^{\circ} 58^{\prime}-110^{\circ} 24^{\prime}$ & $37^{\circ} 49^{\prime}-38^{\circ} 5^{\prime}$ & $1200-1300$ & 406.9 & 8.1 \\
\hline $\begin{array}{c}\text { Shenmu County, } \\
\text { Shaanxi Province }\end{array}$ & SM & $107^{\circ} 20^{\prime}-111^{\circ} 30^{\prime}$ & $37^{\circ} 27.5^{\prime}-39^{\circ} 22.5^{\prime}$ & $1200-1300$ & $250-440.8$ & 8.5 \\
\hline \multicolumn{7}{c}{ AMP: annual mean precipitation; ${ }^{2}$ AMT: annual mean temperature. }
\end{tabular}

Table 2. Seed morphological characteristics of Amygdalus pedunculata Pall. (Mean \pm Standard Deviation).

\begin{tabular}{cccccc}
\hline Species & $\begin{array}{c}\text { Thousand-Seed } \\
\text { Weight } \mathbf{( g )}\end{array}$ & $\begin{array}{c}\text { Thousand-Kernel } \\
\text { Weight } \mathbf{( g )}\end{array}$ & $\begin{array}{c}\text { Single-Seed } \\
\text { Volume }\left(\mathbf{m m}^{\mathbf{3}}\right)\end{array}$ & $\begin{array}{c}\text { Single-Kernel } \\
\text { Volume }\left(\mathbf{m m}^{\mathbf{3}}\right)\end{array}$ & $\begin{array}{c}\text { Kernel Rate } \\
\mathbf{( \% )}\end{array}$ \\
\hline YY-1 & $746.27 \pm 0.35 \mathrm{a}$ & $183.76 \pm 1.47 \mathrm{a}$ & $1532.09 \pm 0.16 \mathrm{a}$ & $371.34 \pm 0.10 \mathrm{a}$ & $24.62 \pm 0.10 \mathrm{~b}$ \\
SM-6 & $448.46 \pm 0.97 \mathrm{~b}$ & $121.08 \pm 0.44 \mathrm{~b}$ & $984.99 \pm 3.22 \mathrm{~b}$ & $250.01 \pm 2.04 \mathrm{~b}$ & $27.00 \pm 0.04 \mathrm{a}$ \\
\hline
\end{tabular}

Means in the same column followed by different letters denote significant differences between YY-1 and SM-6 of Amygdalus pedunculata $(p<0.05)$.

Donors were the leaves of $A$. fruticosa, H. mongolicum, S. vulgaris, and H. rhamnoides, which were collected from the natural forest of Xiaotuhao township, Yulin City, Shaanxi Province, China in October 2016. Fresh and healthy plants were selected and leaf samples were taken. The leaf samples were separated, air-dried, milled, and spared. 


\subsection{The Aqueous Leaf Extracts Preparation}

The experiment was conducted on aqueous extracts from leaves of A. fruticosa, H. mongolicum, S. vulgaris, and H. rhamnoides were prepared by the methods of Le Rouzic et al. [28]: soaking $200 \mathrm{~g}$ of plant powder in $1000 \mathrm{~mL}$ of distilled water and then keeping the mixtures at room temperature for $20-25{ }^{\circ} \mathrm{C}$ for $48 \mathrm{~h}$. The mixtures were then filtered through 300 muslin cloth, and the samples were centrifuged using a micro centrifuge (TG18G-II, Hunan Kaida, Hunan, China) at $3500 \mathrm{rpm}$ for $20 \mathrm{~min}$. The supernatants are hereafter referred to as the undiluted extracts. The extracts obtained were diluted with distilled water to final concentrations of 0 (CK), 0.025 (T1), 0.05 (T2), 0.1 (T3), 0.15 (T4) and $0.2 \mathrm{~g} \cdot \mathrm{mL}^{-1}(\mathrm{~T} 5)$, respectively. The aqueous leaf extracts were stored in a refrigerator (HX-30-620E, Dongguan Haoxin, Dongguan, China) at $4{ }^{\circ} \mathrm{C}$ until use.

\subsection{Seed Germination Experiment}

The method according to Zhang et al. is as follows [25]. Plump and uniform A. pedunculata seeds (kernels) without any pest infestation were carefully selected and soaked in distilled water for 1 day before being disinfected with a $1 \% \mathrm{KMnO}_{4}$ (potassium permanganate) solution for $15 \mathrm{~min}$. The seeds were then rinsed with sterile distilled water and air-dried in a clean bench. Two layers of filter paper were placed into autoclaved petri dishes containing $5 \mathrm{~mL}$ of distilled water or different concentrations of the prepared aqueous leaf extracts. Then, 25 seeds of each cultivar of A. pedunculata were laid uniformly in each petri dish $(12 \mathrm{~cm}$ in diameter). All treatments had four replications. The prepared petri dishes were incubated in an illuminated incubator at $18 / 23{ }^{\circ} \mathrm{C}$ (night/day) at a light intensity of $3000 \mathrm{Lx}$ with a $12 \mathrm{~h}$ light/dark photoperiod and humidity of $45 \%-60 \%$. In addition, the number of germinated seeds was noted every $24 \mathrm{~h}$ for 10 days, according to the method of Wang et al. [29]. The germination potential, germination rate, and germination index were calculated using the Equations (1)-(3) as follows:

$$
\begin{gathered}
\text { Germination potential }(\%)=\frac{\text { the numbers of seed germination in the third day }}{\text { the total numbers of seeds }} \times 100 \\
\text { Germination rate }(\%)=\frac{\text { the numbers of seed germination in the tenth day }}{\text { the total numbers of seeds }} \times 100 \\
\text { Germination index }(G I)=\sum\left(\frac{G t}{D t}\right)
\end{gathered}
$$

where $G t$ is the number of seeds emerging on a given day, and $D t$ is the time after setting the seeds for germination.

\subsection{Seedling Growth Experiment}

After the germination test, 60 strains of consistently growing seedlings were randomly selected from each treatment. Plants were cultivated in 32 plastic plug holes, each of which contained $10 \mathrm{~g} \mathrm{(1:1)}$ of a sterilized vermiculite and perlite mixture. The plugs were placed randomly in a cultivate frame-type artificial climate chamber for one month under the same culture conditions as for seedling growth. During the seedling growth experiments, $10 \mathrm{~mL}$ of different concentrations of shrub aqueous leaf extracts were poured into different treatments every 5 days, and the same volume of distilled water was poured into the control. The length of each seedling and root was measured. The activity of catalase (CAT) was determined by ultraviolet spectrophotometry (UV-2450, Shimadzu Corporation, Kyoto, Japan) [30], peroxidase (POD) was determined by the methyl catechol method [31], and superoxide dismutase (SOD) was determined by the nitro blue tetrazolium photoreduction method [32]. The malondialdehyde (MDA) content was determined by the 2-thiobarbituric acid reaction method [33]. Fresh leaf tissue $(0.5 \mathrm{~g})$ was homogenized in an ice bath in $10 \mathrm{~mL}$ of chilled $0.05 \mathrm{~mol} \cdot \mathrm{L}^{-1}$ phosphate buffer $(\mathrm{pH} 7.8)$ containing $1 \%(w / v)$ soluble 
polyvinyl pyrrolidine (PVP). The homogenates were centrifuged at $4{ }^{\circ} \mathrm{C}$ for $20 \mathrm{~min}$ at $15,000 \mathrm{rpm}$, and the resulting supernatants were used for the determination of MDA. The malondialdehyde content reaction mixture consisted of $0.2 \mathrm{~mL}$ enzyme extract and $5 \mathrm{~mL} 0.5 \%$ glucosinolates barbituric acid (TBA), the final solution was analyzed with the spectrophotometer at 3 different wavelengths $(532 \mathrm{~nm}, 600 \mathrm{~nm}$, and $450 \mathrm{~nm}$ ). Total chlorophyll contents of fresh brassica leaves were determined via the method detailed in Arnon [34]. Fresh leaf tissue ( $0.5 \mathrm{~g})$ was placed in $10 \mathrm{~mL} 80 \%$ acetone, until the leaf completely became white, then we added $80 \%$ acetone to $25 \mathrm{~mL}$, the final solution was analyzed with the spectrophotometer at 3 different wavelengths $(663 \mathrm{~nm}, 646 \mathrm{~nm}$, and $470 \mathrm{~nm})$. Root activity was assessed using the triphenyl tetrazolium chloride reduction method [31]. Fresh root tissue $(0.5 \mathrm{~g})$, $5 \mathrm{~mL} 0.4 \%$ triphenyl tetrazolium chloride (TTC), $5 \mathrm{~mL} 0.067 \mathrm{~mol} \cdot \mathrm{L}^{-1}$ phosphate buffer put in $37^{\circ} \mathrm{C}$ incubator in the dark for $2 \mathrm{~h}$, and then added to $2 \mathrm{~mL} 1 \mathrm{~mol} \cdot \mathrm{L}^{-1} \mathrm{H}_{2} \mathrm{SO}_{4}$. Finally we put out of the roots into another $10 \mathrm{~mL}$ test tube, added to $10 \mathrm{~mL}$ methanol, put in $30-40{ }^{\circ} \mathrm{C}$ incubator in the dark, until the roots completely became white. The final solution was analyzed with the spectrophotometer at a wavelength of $485 \mathrm{~nm}$.

The allelopathy index (RI), obtained from Equations (4) and (5) [35], was used to indicate the allelopathic effects of aqueous leaf extracts on seedlings' seed germination, seedling growth, and physiological characteristics:

$$
\begin{aligned}
& R I=1-C / T(T \geq C) \\
& R I=T / C-1(T<C)
\end{aligned}
$$

where $T$ is the treatment value and $C$ is the control value. A positive $R I$ value indicated a promotional effect of allelochemicals on A. pedunculata, whereas a negative value indicated allelopathic inhibition. The synthetic inhibiting effect (SE) value was used as an indicator to evaluate allelopathic effects, calculated as the average RI value of each treatment index [25].

\subsection{Statistical Analysis}

All analyses were conducted using a completely randomized design. Data were statistically processed in SPSS 22.0 (SPSS Inc., Chicago, IL, USA), using one-way ANOVA with the lowest standard deviations test for analysis. Comparisons with $p<0.05$ were considered significantly different. Figures were created in OriginPro 9.0 (Origin Lab Corporation, Northampton, MA, USA).

\section{Results}

\subsection{Effects of Shrub Aqueous Leaf Extracts on A. pedunculata Seed Germination}

Four species of shrub aqueous leaf extracts showed low concentration promotion and high concentration inhibition on the seed germination indicators of A. pedunculata. Among the four-sampled species, H. mongolicum aqueous leaf extracts showed the strongest allelopathy promotional effects on germination potential, germination rate, and germination index of YY-1 (T1, 31.15\%, 14.81\%, and 26.97\% increases, respectively) and SM-6 (T1, 19.70\%, 9.64\%, and $24.92 \%$ increases, respectively), followed by $A$. fruticosa and S. vulgaris. In addition, H. rhamnoides aqueous leaf extracts had the strongest inhibitory effect on seed germination of A. pedunculata, and death occurred at concentrations of T4 and T5 (Figure 1a-f). 


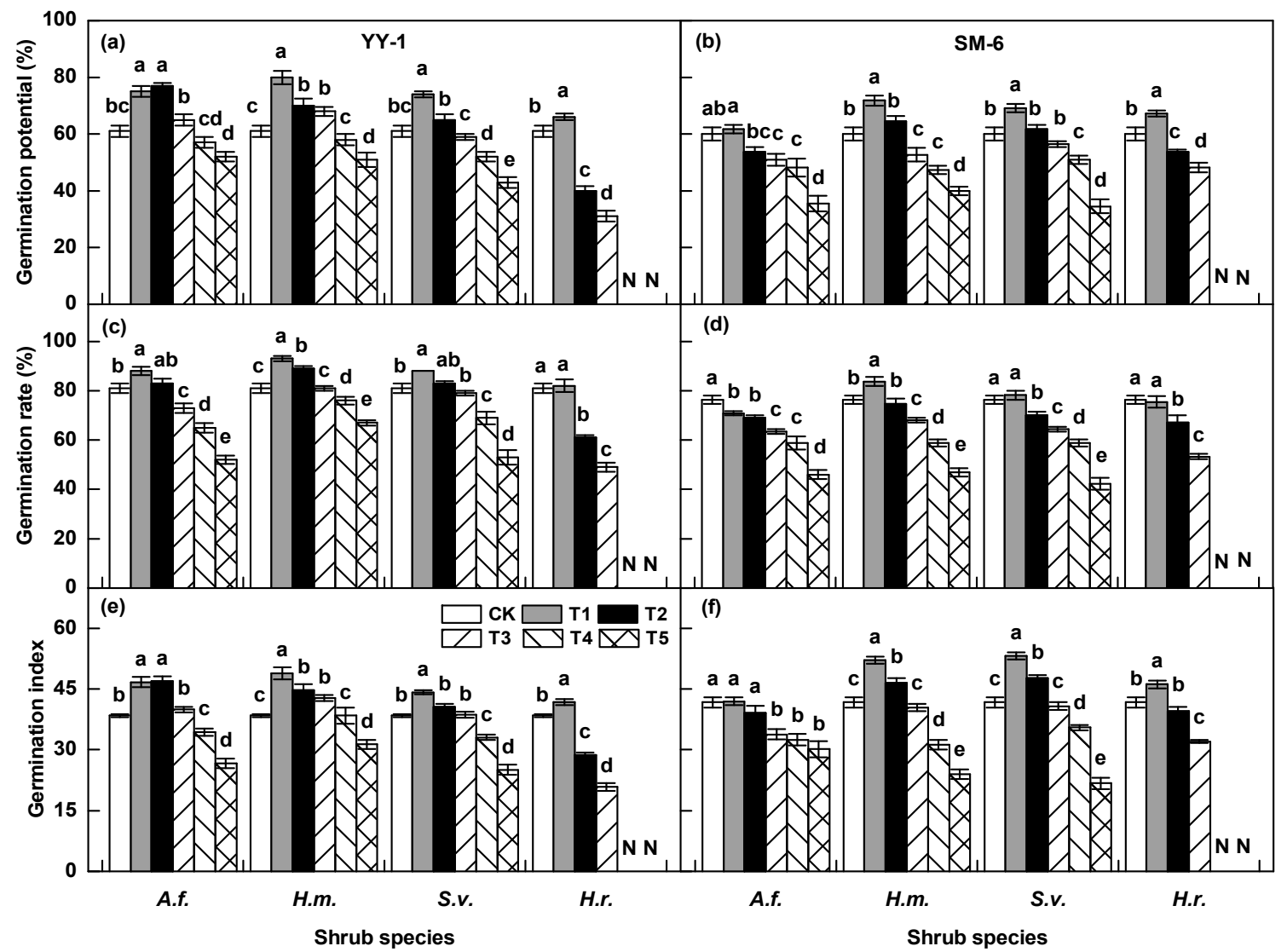

Figure 1. Effect of different concentrations of four shrub species' aqueous leaf extracts on seed germination of Amygdalus pedunculata. (a-f). Data (Mean \pm Standard Error, $n=42)$ of the germination potential $(\mathbf{a}, \mathbf{b})$, germination rate $(\mathbf{c}, \mathbf{d})$, and germination index $(\mathbf{e}, \mathbf{f})$ of the target $A$. pedunculata species of YY-1 from Yuyang County (YY) and SM-6 from Shenmu County (SM) exposed to six concentrations (0 (CK), 0.025 (T1), 0.05 (T2), 0.1 (T3), 0.15 (T4), and $0.2 \mathrm{~g} \cdot \mathrm{mL}^{-1}$ (T5)) of aqueous leaf extracts from the donor species-Amorpha fruticosa (A.f.), Hedysarum mongolicum (H.m.), Sabina vulgaris (S.v.), and Hippophae rhamnoides (H.r.) - for 10 days in petri dishes (four replicates of 25 seeds each). $\mathrm{N}$ means no value (the seeds did not germinate and died). Different little letters indicate significant difference $(p<0.05)$. Vertical bars represent standard errors $(n=4)$.

\subsection{Effects of Shrub Aqueous Leaf Extracts on A. pedunculata Seedling Growth}

The treatment with A. fruticosa, H. mongolicum, and S. vulgaris showed significant promotional effects $(p<0.05)$ on the seedling and root length of YY-1 (T2, seedling length, $10.89 \%, 22.15 \%$ and $12.86 \%$ increases; root length, $14.81 \%, 31.96 \%$ and $23.46 \%$ increases, respectively) and SM- 6 (T1, seedling length, $0.27 \%, 0.24 \%$, and $0.29 \%$ increases; root length, $1.49 \%, 3.23 \%$, and $7.30 \%$ increases, respectively) at the concentration of T1and T2 (Figure 2a-d). However, the treatment with H. rhamnoides led to a decrease of the seedling and root length of YY-1 (T1, 9.80\% and 19.65\% decreases) and SM-6 (T1, 37.37\% and $33.28 \%$ decreases, $p<0.05$ ) at all concentrations, but the inhibitory effect was enhanced at high concentrations (T4 and T5). 


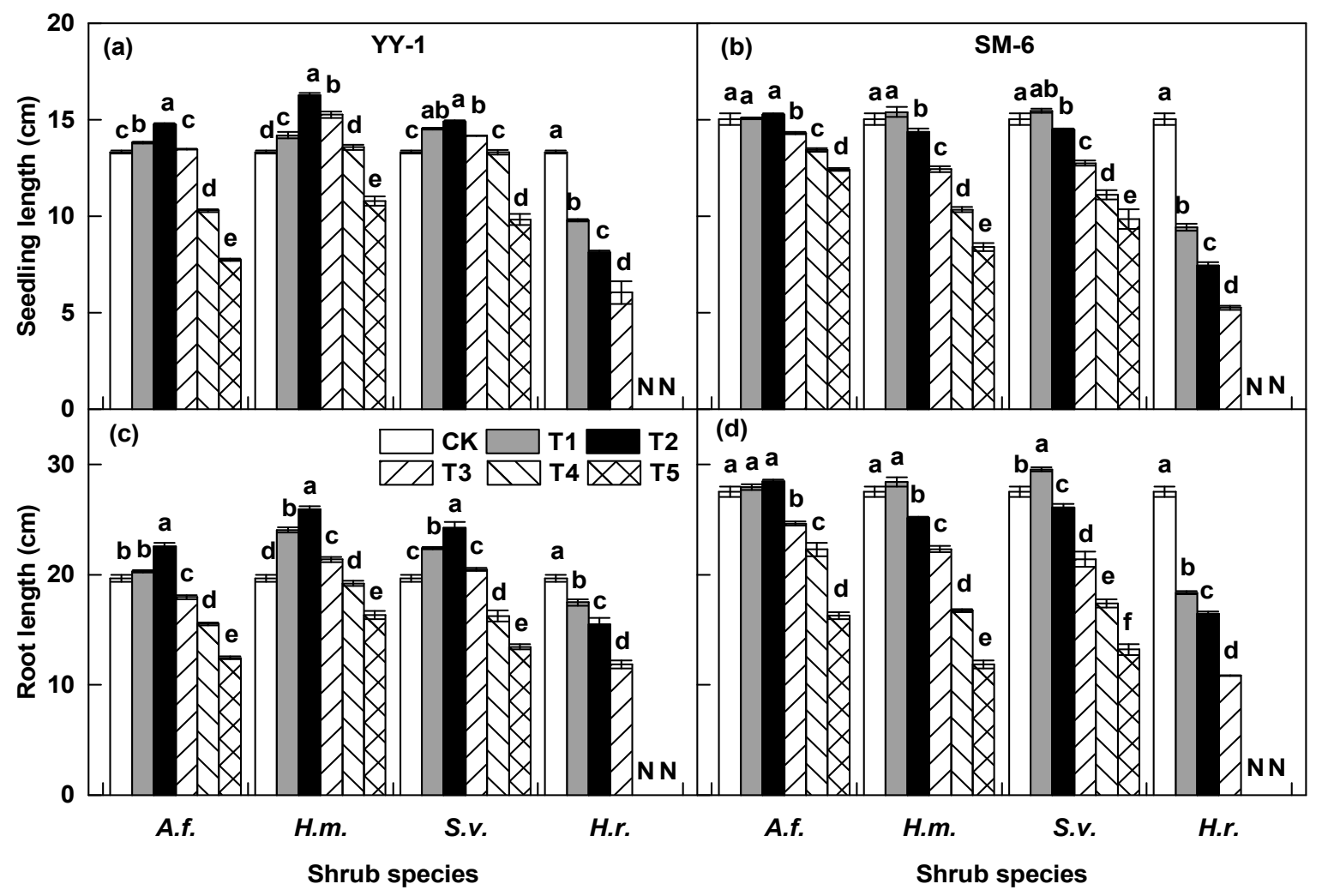

Figure 2. Effect of shrub aqueous leaf extracts on length of seedling and root of Amygdalus pedunculata. (a-d). Data (Mean \pm Standard Error, $n=42$ ) of the seedling length $(\mathbf{a}, \mathbf{b})$ and root length (c,d) of the target A. pedunculata species of YY-1 and SM-6 exposed to six concentrations 0 (CK), 0.025 (T1), 0.05 (T2), 0.1 (T3), 0.15 (T4), and $0.2 \mathrm{~g} \cdot \mathrm{mL}^{-1}$ (T5) of aqueous leaf extracts from the donor species-Amorpha fruticosa (A.f.), Hedysarum mongolicum (H.m.), Sabina vulgaris (S.v.), and Hippophae rhamnoides (H.r.) - Plants were cultivated in 32 plastic plug holes, each of which contained $10 \mathrm{~g}$ (1:1) of a sterilized vermiculite and perlite mixture. The plugs were placed randomly in a cultivate frame-type artificial climate chamber for one month. During the seedling growth experiments, $10 \mathrm{~mL}$ of different concentrations of shrub aqueous leaf extracts were poured into different treatments every 5 days, and the same volume of distilled water was poured into the control. $\mathrm{N}$ means no value (all the plants death and no relevant indicators have been detected). Different little letters indicate significant difference $(p<0.05)$. Vertical bars represent standard errors $(n=4)$.

\subsection{Effects of Shrub Aqueous Leaf Extracts on Physiological Traits of A. pedunculata Seedlings}

\subsubsection{Enzyme Activity}

YY-1 and SM-6 showed an increasing trend of CAT activities at concentrations of T1 to T3 for aqueous leaf extracts of A. fruticosa, H. mongolicum, and S. vulgaris (Figure 3a,b), but POD and SOD activity showed a decreasing trend with increasing aqueous leaf extracts concentrations (Figure $3 \mathrm{c}-\mathrm{f}$ ). The results indicated that the stress level of $A$. pedunculata was unable to regulate the enzyme itself at low concentrations for these shrub aqueous leaf extracts; thus, the seedling of $A$. pedunculata grew better. In addition, at the same concentration, $H$. rhamnoides aqueous leaf extracts on CAT, POD, and SOD activity of YY-1 and SM-6 were significantly lower than that of A. fruticosa, H. mongolicum, and S. vulgaris (Figure 3a-f), implying that the YY-1 and SM-6 seedlings suffered greater stress from $H$. rhamnoides aqueous leaf extracts and died at high concentrations (T4 and T5). 


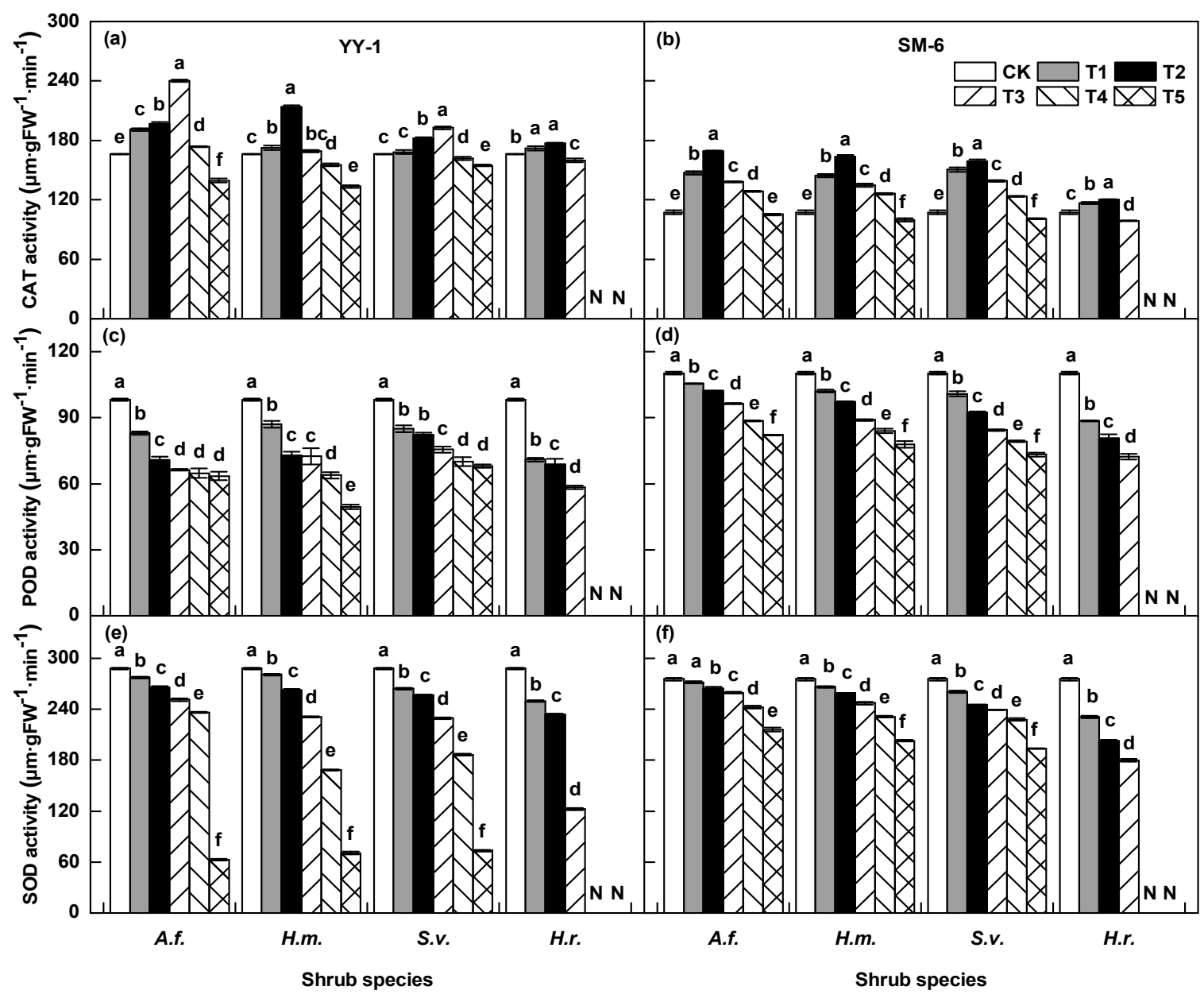

Figure 3. Effect of different concentrations of four shrub species' aqueous leaf extracts on enzyme activity of $A$. pedunculata. (a-f). Data (Mean \pm Standard Error, $n=42$ ) of the activity of catalase (CAT) $(\mathbf{a}, \mathbf{b})$, peroxidase (POD) (c,d), and superoxide dismutase (SOD) (e,f) of the target A. pedunculata species of YY-1 and SM-6 seedlings exposed to six concentrations 0 (CK), 0.025 (T1), 0.05 (T2), 0.1 (T3), 0.15 (T4), and $0.2 \mathrm{~g} \cdot \mathrm{mL}^{-1}$ (T5) of aqueous leaf extracts from the donor species-Amorpha fruticosa (A.f.), Hedysarum mongolicum (H.m.), Sabina vulgaris (S.v.), and Hippophae rhamnoides (H.r.). N means no value (all the plants death and no relevant indicators have been detected). Different little letters indicate significant difference $(p<0.05)$. Vertical bars represent standard errors $(n=4)$.

\subsubsection{Malondialdehyde Content}

The treatment with A. fruticosa, H. mongolicum, S. vulgaris, and H. rhamnoides increased MDA contents in seedlings of YY-1and SM-6 at all concentration (Figure 4a,b). Among the four-sampled species, $H$. rhamnoides aqueous leaf extracts showed the strongest allelopathy promotional effects on MDA contents in seedlings of YY-1 (T3, 177.73\% increase, $p<0.05)$ and SM-6 (T3, $143.26 \%$ increase, $p<0.05$ ), indicating that $H$. rhamnoides aqueous leaf extracts had stronger effects on the lipid membrane peroxidation of YY-1 and SM-6. Cell membrane permeability was also greater and cell damage was higher, leading to poorer growth of the A. pedunculata seedling. The aqueous leaf extracts of $A$. fruticosa, $H$. mongolicum, and $A$. fruticosa did not exceeded their own range for the degree of membrane damage of YY- 1 and SM-6, so the seedlings grew better. 


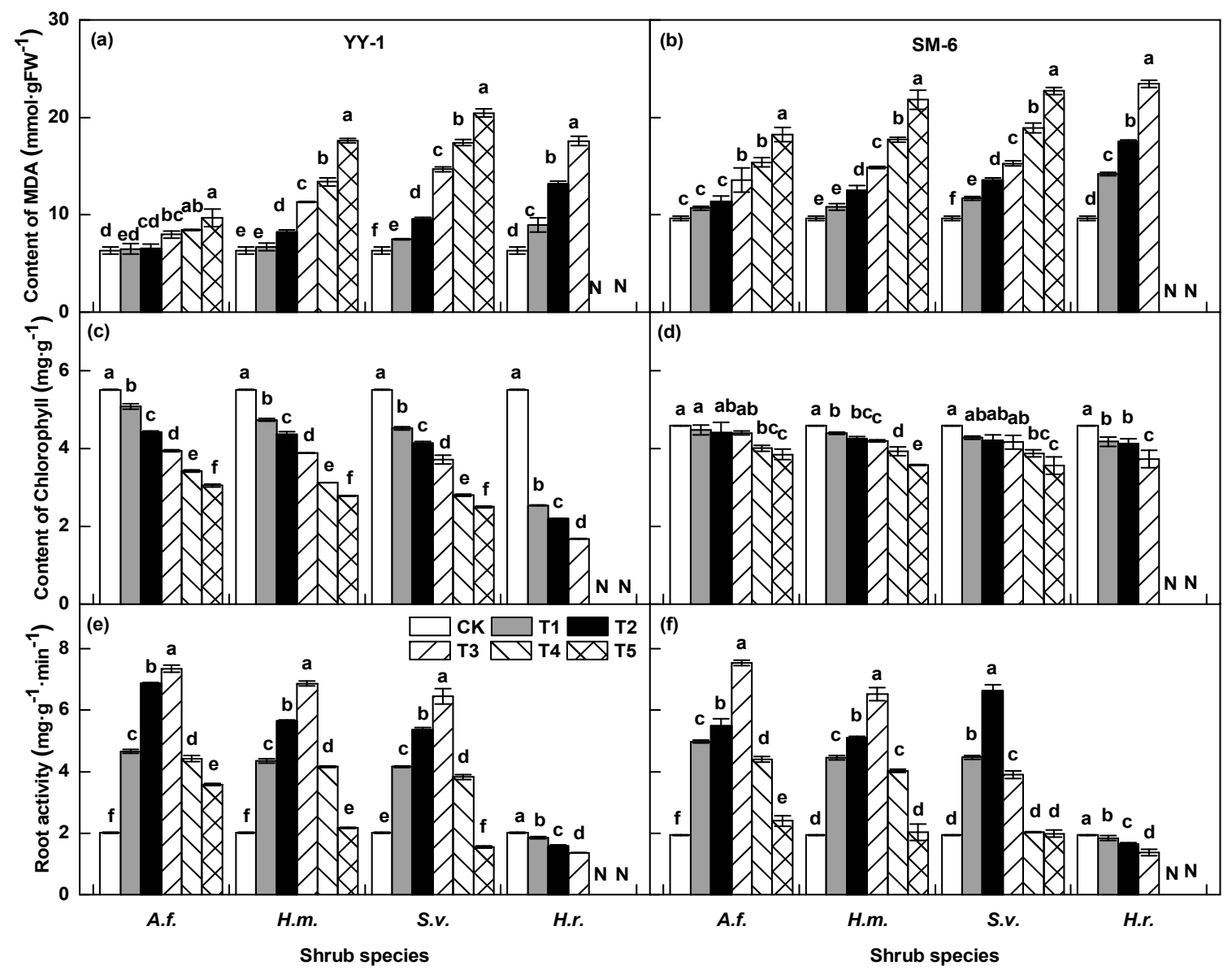

Figure 4. Effect of different concentrations of four shrub species' aqueous leaf extracts on MDA, chlorophyll content, and root activity of A. pedunculata. (a-f). Data (Mean \pm Standard Error, $n=42$ ) of MDA content $(\mathbf{a}, \mathbf{b})$, chlorophyll content $(\mathbf{c}, \mathbf{d})$, and root activity $(\mathbf{e}, \mathbf{f})$ of the target $A$. pedunculata species of YY-1 and SM-6 seedlings exposed to six concentrations 0 (CK), 0.025 (T1), 0.05 (T2), 0.1 (T3), 0.15 (T4), and $0.2 \mathrm{~g} \cdot \mathrm{mL}^{-1}$ (T5) of aqueous leaf extracts from the donor species-Amorpha fruticosa (A.f.), Hedysarum mongolicum (H.m.), Sabina vulgaris (S.v.), and Hippophae rhamnoides (H.r.). N means no value (all the plants death and no relevant indicators have been detected). Different little letters indicate significant difference $(p<0.05)$. Vertical bars represent standard errors $(n=4)$.

\subsubsection{Chlorophyll Content}

The chlorophyll contents of YY-1 and SM-6 showed similar trends to POD and SOD activity. The chlorophyll content in seedling of YY-1 and SM- 6 decreased with an increase in the concentration of four species of shrub aqueous leaf extracts and showed an inhibitory effect (Figure 4c,d). The variance analysis showed that aqueous leaf extracts of A. fruticosa, H. mongolicum, and S. vulgaris had no significant difference $(p>0.05)$ on the chlorophyll content in the SM-6 seedling. In addition, $H$. rhamnoides aqueous leaf extracts was significantly lower on the chlorophyll content of YY-1 (T3, 69.51\% decrease, $p<0.05)$ and SM-6 (T3, 18.56\% decrease, $p<0.05)$ than that of the control, illustrating a stronger inhibitory effect on YY-1 and SM-6 seedlings in terms of light absorption and utilization efficiency; hence, seeding growth and death at high concentrations were restrained.

\subsubsection{Root Activity}

The effects of A. fruticosa, H. mongolicum, and S. vulgaris aqueous leaf extracts on the root activity of YY-1 and SM-6 under five concentration gradients showed an initial increase followed by a decrease with increasing extracts concentration (Figure 4e,f). These results suggest that the stress level gradually increased on the root system of YY-1 and SM-6, which may inhibit root growth. 
As dehydrogenase activity gradually increased, root activity decreased. The treatments with A. fruticosa and $H$. mongolicum produced significant promotional effects on the root activity of YY-1 $(265.67 \%$ and $241.79 \%$ increases, respectively, $p<0.05)$ and SM-6 $(288.66 \%$ and $236.08 \%$ increases, respectively, $p<0.05$ ) at the concentrations of T3. However, H. rhamnoides aqueous leaf extracts had the strongest inhibitory effect on root activity of YY-1 (32.34\% decrease, $p<0.05)$ and SM-6 $(28.87 \%$ decrease, $p<0.05)$ at the concentrations of $\mathrm{T} 3$.

\subsection{Synthetic Inhibiting Effect}

Eleven indicators, including germination potential, germination rate, germination index, length of seedling and root, enzyme activity and so on, were used to analyze the allelopathy SE value to reflect the total allelopathic intensity of four species of shrub aqueous leaf extracts on YY-1 and SM-6. Aqueous leaf extracts of A. fruticosa, H. mongolicum, and S. vulgaris at concentrations of T1 to T3 were positive and had promotional effects on YY-1 and SM-6 (Figure 5a,b). At the concentration of T2, the SE values of YY-1 peaked at $0.06,0.12$, and 0.09 , respectively. The SE values of the four species of shrub aqueous leaf extracts on YY-1 were as follows: H. mongolicum $>$ S. vulgaris $>$ A. fruticosa $>$ H. rhamnoides (Figure 5a). The SE values of four species of shrub aqueous leaf extracts at the concentration of T1 to T3 on SM-6 were as follows: H. mongolicum $>$ A. fruticosa $>$ S. vulgaris $>$ H. rhamnoides (Figure 5b). In addition, $\mathrm{SE}$ values of $H$. rhamnoides aqueous leaf extracts at all tested concentrations on YY-1 and SM-6 were negative, indicating an inhibitory effect.

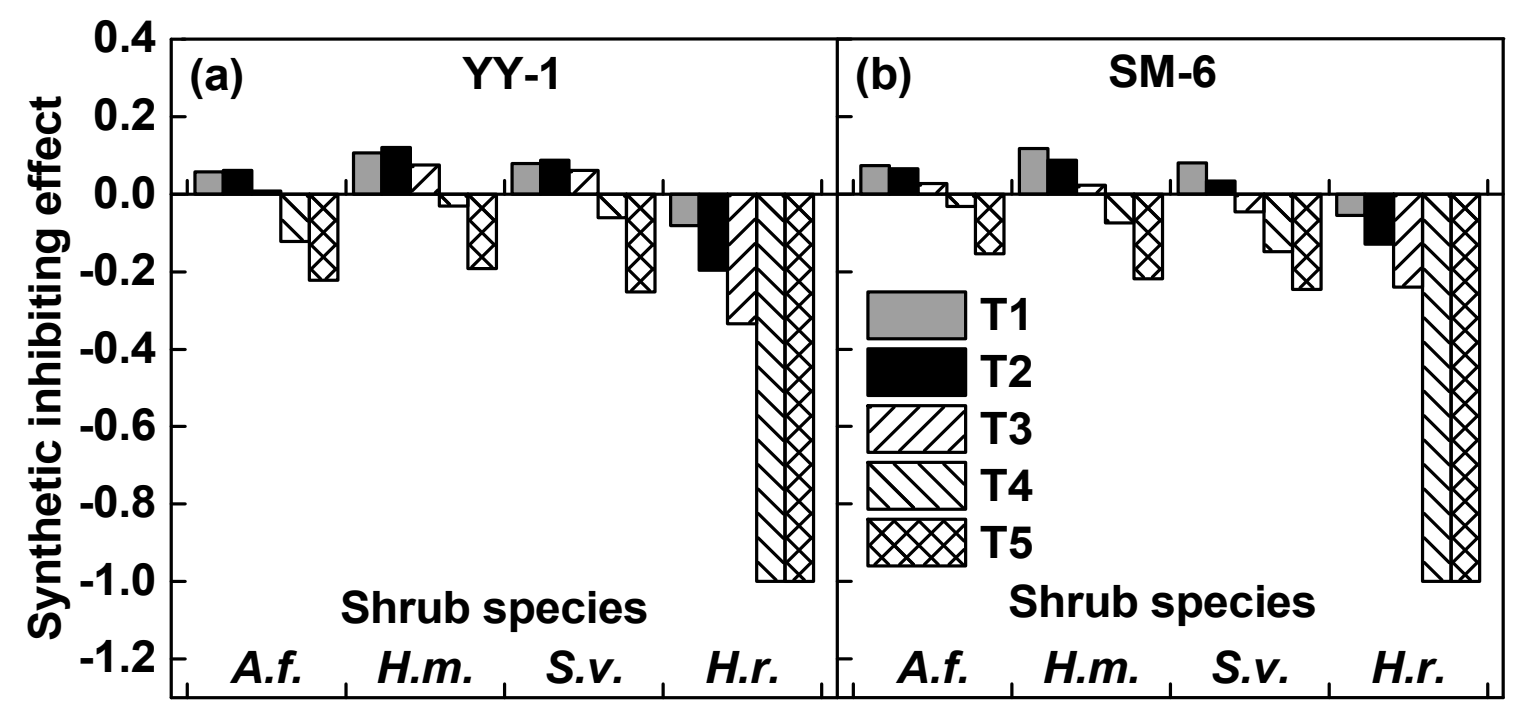

Figure 5. Synthetic inhibiting effect of the aqueous leaf extracts from the donor species on the target $A$. pedunculata species. The synthetic inhibiting effect (SE) value was calculated as the average allelopathy index $(R I)$ value of all indicators of each treatment of the target $A$. pedunculata species of YY-1 (a) and SM-6 (b). The concentrations of 0 (CK), 0.025 (T1), 0.05 (T2), 0.1 (T3), 0.15 (T4), and $0.2 \mathrm{~g} \cdot \mathrm{mL}^{-1}$ (T5) of aqueous leaf extracts from the donor species-Amorpha fruticosa (A.f.), Hedysarum mongolicum (H.m.), Sabina vulgaris (S.v.), and Hippophae rhamnoides (H.r.).

\section{Discussion}

The seed germination potential could reflect germination speed and uniformity of the seed germination of the receptor plant. The germination rate determines individual survival and population quantity, while the germination index generally reflects the receptor plant seeds' germination process [24]. In this study, four species of shrub leaf extracts at a concentration of T1 showed significant promotional effects on the germination potential, germination rate, and germination index of YY-1 and SM-6 (excluding the germination rate of SM-6). Inhibitory effects were enhanced at high concentrations (T4 and T5). The germination index of SM-6 showed a stronger inhibitory effect than that of YY-1. In addition, H. rhamnoides leaf extract had the strongest inhibitory effect on seed 
germination indicators of A. pedunculate, and death occurred at concentrations of T4 and T5. A. fruticose, $H$. mongolicum, and $S$. vulgaris leaf extracts showed significant promotional effects on seedling and root length at concentrations of T1 and T2 for YY-1 and SM-6, but the inhibitory effect was enhanced as leaf extract concentrations increased. H. rhamnoides leaf extract had the strongest inhibitory effect on the length and weight of YY-1 and SM-6 seedlings and roots.

Four species of shrub leaf extracts tested for seed germination and seedling growth indicators on YY-1 and SM-6 showed significant promotional effects at low concentrations and significant inhibitory effects at high concentrations. These findings concurred with those of Arowosegbe and Afolayan [36], who reported that stem and root extracts at low concentrations had stimulatory effects on the seedling growth of lettuce and tomatoes, but leaf extracts more potent than stem and root extracts completely inhibited seed germination and tomato seedling growth at a high concentration $\left(10 \mathrm{mg} \cdot \mathrm{mL}^{-1}\right)$. However, the effects of $H$. rhamnoides leaf extracts on seed germination and seedling growth of YY-1 and SM-6 aligned with the results of Mahmoud et al. [37], who stated that jatropha extracts suppressed seed germination and seedling growth in wheat as found in ex-situ bioassay, but seed germination and initial growth at low concentrations $(0.5 \%$ and $5 \%)$ had higher tolerance than at high concentrations (10\% and $20 \%)$.

Aliskan and Terzi [38] identified seed size as an important factor affecting allelopathic sensitivity. Smaller seeds have fewer mineral nutrient reserves and rely on the absorption of material components from external leachate. In this study, the allelopathic effects and concentration response of the four species of shrub leaf extracts on seed germination and seedling growth of YY-1 and SM-6 may be related to differences between YY-1 and SM-6 seeds: YY-1 seeds (single-seed volume $\approx 1532.09 \mathrm{~mm}^{3}$; single-kernel volume $\approx 371.34 \mathrm{~mm}^{3}$; thousand-seed weight $\approx 746.27 \mathrm{~g}$; thousand-kernel weight $\approx 183.76 \mathrm{~g}$ ) are larger and heavier than those of SM-6 (single-seed volume $\approx 984.99 \mathrm{~mm}^{3}$; single-kernel volume $\approx 250.01 \mathrm{~mm}^{3}$; thousand-seed weight $\approx 448.46 \mathrm{~g}$; thousand-kernel weight $\approx 121.08 \mathrm{~g}$ ) (Table 2 ). Therefore, SM-6 appears to be more dependent on the absorption of four species of shrub leaf extracts than YY-1 during seed germination and seedling growth. Thomaszewishi and Thimann [39] found that most allelochemicals inhibit growth by inhibiting gibberellin and auxin receptor levels. Yu and Matsui [40] discovered that allelochemicals resist the absorption of nutrients such as $\mathrm{K}^{+}, \mathrm{Ca}^{2+}, \mathrm{Mg}^{2+}$, and $\mathrm{PO}^{3-}$ by changing the plant's absorptive capacity. Therefore, the differences in seed germination and seedling growth indicators in SM-6 and YY-1 for four species of shrub leaf extract may be related to the allelochemicals in different leaf extracts.

Enzyme activity (CAT, POD, and SOD) and chlorophyll content decreased with an increase in concentrations of four species of shrub leaf extracts. The trend for MDA content was opposite, root activity tended to increase first and then decrease. These results are consistent with research findings of Zeng et al. [41], who used the allelochemical secalonic acid F (SAF) treated with Sorghum Vulgare Pers., Bidens Pilosa L., and Echinochloa crus-galli (L.) Beauv. The receptor plant roots' biological membrane permeability increased significantly; SOD and POD activity decreased significantly. MDA content increased substantially, chlorophyll content decreased, and SAF demonstrated membrane peroxidation that damaged the structure of the entire lipid membrane and weakened plant tissue protection. Meanwhile, Roshchina and Roshchina [42] reported that some polyphenols can inhibit SOD and POD activity in plants, leading to an increase of active oxygen and activation of lipid peroxidation. Chlorophyll can absorb and transfer light energy. The content and composition of chlorophyll determines plants' absorption and utilization efficiency of different light; therefore, it is often considered an important indicator of photosynthetic physiology [25]. Many studies have indicated that allelochemicals can affect every aspect of plant growth and plants' physiological and biochemical processes [43-47]. An increase in inhibitory allelochemicals such as terpenes, furanones, phenol abscisic acid, coumarin, and so on, can hinder seed germination and seedling growth through physiological and biochemical processes [48]. 


\section{Conclusions}

The aqueous leaf extracts of A. fruticosa, H. mongolicum, and S. vulgaris at low concentrations (T1 and T2) showed significant promotional effects on seed germination and seedling growth indicators for Amygdalus pedunculata Pall. At high concentrations (T4 and T5), the inhibitory effects were enhanced as aqueous leaf extracts concentrations increased. In addition, $H$. rhamnoides aqueous leaf extracts had the strongest inhibitory effect on seed germination and seedling growth of YY-1 and SM-6. Enzyme activity (CAT, POD, and SOD) and chlorophyll content decreased with an increase in the concentrations of four species of shrub aqueous leaf extracts; however, the trend of MDA content was opposite (root activity tended to increase first and then decrease). The SE values of aqueous leaf extracts from four species of shrub on YY-1 were as follows: H. mongolicum $>$ S. vulgaris $>$ A. fruticosa $>H$. rhamnoides (T1 to T3). For SM-6, SE values were as follows: H. mongolicum $>$ A. fruticosa $>$ S. vulgaris $>$ H. rhamnoides (T1 to T3). Therefore, H. mongolicum and S. vulgaris appear to be the most suitable mixed tree species for YY-1, while H. mongolicum and A. fruticosa are most suitable for SM-6, and at a relatively low density mixed more securely. H. rhamnoides should not be mixed with YY-1 and SM-6.

Author Contributions: J.W. designed the experiments; X.W. wrote the paper; R.Z., Y.H., S.F., and X.M. performed the experiments and analyzed the data; and Y.Z., A.S., and R.R., participated in the experiment and help to complete the experiments.

Funding: This research was supported by National Key Research and Development Program of China "Eco-security technology for coal mining bases in the Northwestern arid desert regions in China" (2017YFC0504400), "Studies on the vegetation rehabilitation and conservation in abandoned coal mining land research" (2017YFC0504402), Plan Project of Scientific and Technological Co-ordination Innovation Engineering of Shaanxi Province (2016KTCL0318) and Yulin City Forestry Science and Technology Plan Projects (K403021528).

Acknowledgments: The authors would like to thank the people from Key Laboratory of Plant Nutrition and the Agri-environment, especially Ruiqi Zhang and You Huang, for their constant and reliable assistance in plant cultivation and physiological and biochemical analysis.

Conflicts of Interest: The authors declare no conflicts of interest.

\section{References}

1. Ekimova, N.V.; Muratova, E.N.; Silkin, P.P. The role of polyploidy in adaptation and settling of steppe shrubs in Central Asia. Russ. J. Genet. 2012, 2, 105-109. [CrossRef]

2. Wang, J.; Ren, H.; Yang, L.; Li, D.; Guo, Q. Soil seed banks in four 22-year-old plantations in South China: Implications for restoration. For. Ecol. Manag. 2009, 258, 2000-2006. [CrossRef]

3. Chu, J.M.; Yang, H.X.; Lu, Q.; Zhang, X.Y. Endemic shrubs in temperate arid and semiarid regions of northern China and their potentials for rangeland restoration. AoB Plants 2015, 7, 1-8. [CrossRef] [PubMed]

4. Schuler, L.J.; Bugmann, H.; Snell, R.S. From monocultures to mixed-species forests: Is tree diversity key for providing ecosystem services at the landscape scale? Landsc. Ecol. 2017, 32, 1499-1516. [CrossRef]

5. Fornara, D.A.; Tilman, D. Plant functional composition influences rates of soil carbon and nitrogen accumulation. J. Ecol. 2008, 96, 314-322. [CrossRef]

6. Kooch, Y.; Bayranvand, M. Composition of tree species can mediate spatial variability of $\mathrm{C}$ and $\mathrm{N}$ cycles in mixed beech forests. For. Ecol. Manag. 2017, 401, 55-64. [CrossRef]

7. Nickmans, H.; Collet, C.; Bonal, D.; Verheyen, K.; Ponette, Q. Tree size and local neighborhood affect foliar nutrient content in a mixed plantation of beech (Fagus sylvatica) and maple (Acer pseudoplatanus). For. Ecol. Manag. 2017, 400, 159-172. [CrossRef]

8. Lamb, E.G.; Kennedy, N.; Siciliano, S.D. Effects of plant species richness and evenness on soil microbial community diversity and function. Plant Soil 2011, 338, 483-495. [CrossRef]

9. Mallick, N.; Mohn, F.H. Reactive oxygen species: Response of algal cells. J. Plant Physiol. 2000, 157, $183-193$. [CrossRef]

10. Sun, Y.F.; Zhang, Y.Q.; Feng, W.; Qin, S.G.; Liu, Z.; Bai, Y.X.; Yan, R.; Fa, K.Y. Effects of xeric shrubs on soil microbial communities in a desert in northern China. Plant Soil 2016, 414, 281-294. [CrossRef] 
11. Isbell, F.; Adler, P.R.; Eisenhauer, N.; Fornara, D.; Kimmel, K.; Kremen, C.; Letourneau, D.K.; Liebman, M.; Polley, H.W.; Quijas, S.; et al. Benefits of increasing plant diversity in sustainable agroecosystems. J. Ecol. 2017, 105, 871-879. [CrossRef]

12. Ehbrecht, M.; Schall, P.; Ammer, C.; Seidel, D. Quantifying stand structural complexity and its relationship with forest management, tree species diversity and microclimate. Agric. For. Meteorol. 2017, 242, 1-9. [CrossRef]

13. Sezen, I.; Ercisli, S.; Cakir, O.; Koc, A.; Temi, E.; Hadziabulic, A. Biodiversity and landscape use of sea buckthorn (Hippophae rhamnoides L.) in the Coruh Valley of Turkey. Erwerbs-Obstbau 2015, 57, $23-28$. [CrossRef]

14. Lai, Z.R.; Zhang, Y.Q.; Liu, J.B.; Wu, B.; Qin, S.G.; Fa, K.Y. Fine-root distribution, production, decomposition, and effect on soil organic carbon of three revegetation shrub species in northwest China. For. Ecol. Manag. 2016, 359, 381-388. [CrossRef]

15. Wei, Q.; Wei, Y.; Wu, H.W.; Yang, X.Y.; Chen, H.L.; Zhang, H.X. Chemical composition, anti-oxidant, and antimicrobial activities of four saline-tolerant plant seed oils extracted by SFC. J. Am. Oil Chem. Soc. 2016, 93, 1173-1182. [CrossRef]

16. Tanaka-Oda, A.; Kenzo, T.; Kashimura, S.; Ninomiya, I.; Wang, L.H.; Yoshikawa, K.; Fukuda, K. Physiological and morphological differences in the heterophylly of Sabina vulgaris Ant. in the semi-arid environment of $\mathrm{Mu}$ Us Desert, Inner Mongolia, China. J. Arid Environ. 2010, 74, 43-48. [CrossRef]

17. Requena, N.; Perez-Solis, E.; Azcón-Aguilar, C.; Jeffries, P.; Barea, J.M. Management of indigenous plant-microbe symbioses aids restoration of desertified ecosystems. Appl. Environ. Microbiol. 2001, 67, 495-498. [CrossRef] [PubMed]

18. Ishii, Y.; Sakamoto, K.; Yamanaka, N.; Wang, L.; Yoshikawa, K. Light acclimation of needle pigment composition in Sabina vulgaris seedlings under nurse plant canopy. J. Arid Environ. 2006, 67, 403-415. [CrossRef]

19. Rice, E.L. Allelopathy, 2nd ed.; Academic Press: New York, NY, USA, 1984; pp. 1-50, 309-315.

20. Ninkovic, V. Volatile interaction between undamaged plants: A short cut to coexistence. In Plant Communication from an Ecological Perspective; Springer: Heidelberg, Germany, 2010; pp. 75-86.

21. Glinwood, R.; Ninkovic, V.; Pettersson, J. Chemical interaction between undamaged plants-Effects on herbivores and natural enemies. Phytochemistry 2011, 72, 1683-1689. [CrossRef] [PubMed]

22. Zhang, C.; Li, X.; Chen, Y.; Zhao, J.; Wan, S.; Lin, Y.; Fu, S. Effects of Eucalyptus litter and roots on the establishment of native tree species in Eucalyptus plantations in South China. For. Ecol. Manag. 2016, 375, 76-83. [CrossRef]

23. Peerzada, A.M.; Ali, H.H.; Chauhan, B.S. Weed management in sorghum (Sorghum bicolor (L.) Moench) using crop competition: A review. Crop Prot. 2017, 95, 74-80. [CrossRef]

24. Siri-Udom, S.; Suwannarach, N.; Lumyong, S. Applications of volatile compounds acquired from Muscodor heveae against white root rot disease in rubber trees (Hevea brasiliensis Müll. Arg.) and relevant allelopathy effects. Fungal Biol. 2017, 121, 573-581. [CrossRef] [PubMed]

25. Zhang, X.X.; Liu, Z.W.; Tian, N.; Luc, N.T.; Zhu, B.C.; Bing, Y.H. Allelopathic effects of decomposed leaf litter from intercropped trees on rape. Turk. J. Agric. For. 2015, 39, 898-908. [CrossRef]

26. Yan, S.; Zou, G.H.; Li, S.J.; Wang, H.; Liu, H.Q.; Zhai, G.W.; Guo, P.; Song, H.M.; Yan, C.J.; Tao, Y.Z. Seed size is determined by the combinations of the genes controlling different seed characteristics in rice. Theor. Appl. Genet. 2011, 123, 1173-1181. [CrossRef] [PubMed]

27. Wang, J.; Lü, B.; Xiao, Z.W.; Yan, J.Z.; Zhang, Y.F. Seed characteristics and hard seed broken methods of Sophora alopecuroides and Thermopsis lanceolata (in Chinese with English abstract). Trans. Chin. Soc. Agric. Eng. 2010, 26, 406-410.

28. Le Rouzic, B.; Thiébaut, G.; Brient, L. Selective growth inhibition of cyanobacteria species (Planktothrix agardhii) by a riparian tree leaf extracts. Ecol. Eng. 2016, 97, 74-78. [CrossRef]

29. Wang, C.Y.; Xiao, H.G.; Zhao, L.L.; Liu, J.; Wang, L.; Zhang, F.; Shi, Y.C.; Du, D.L. The allelopathic effects of invasive plant Solidago canadensis on seed germination and growth of Lactuca sativa enhanced by different types of acid deposition. Ecotoxicology 2016, 25, 555-562. [CrossRef] [PubMed]

30. Li, Q.; Cai, J.; Jiang, Z.M.; Zhang, S.X. Allelopathic effects of walnut leaves leachate on seed germination, seedling growth of medicinal plants. Allelopath. J. 2010, 26, 235-242. 
31. Wang, C.Z.; Zhang, D.J.; Zang, J.; Ji, T.W.; Tang, Z.Q.; Zhao, Y.Y. Allelopathic effects of volatile compounds from Eucalyptus grandis on Vigna radiata, Raphanus sativus and Lactuca sativa. Allelopath. J. 2015, 36, $273-282$.

32. Fu, J.M.; Huang, B.R. Involvement of antioxidants and lipid peroxidation in the adaptation of two cool-season grasses to localized drought stress. Environ. Exp. Bot. 2001, 45, 105-114. [CrossRef]

33. Hodges, D.M.; DeLong, J.M.; Forney, C.F.; Prange, R.K. Improving the thiobarbituric acid-reactive-substances assay for estimating lipid peroxidation in plant tissues containing anthocyanin and other interfering compounds. Planta 1999, 207, 604-611. [CrossRef]

34. Arnon, D.I. Copper enzymes in isolated chloroplast polyphenol oxidase in Beta vulgaris. Plant Physiol. 1949, 24, 1-15. [CrossRef] [PubMed]

35. Williamson, G.B.; Richardson, D. Bioassays for allelopathy: Measuring treatment responses with independent controls. J. Chem. Ecol. 1988, 14, 181-187. [CrossRef] [PubMed]

36. Arowosegbe, S.; Afolayan, A.J. Germination and growth inhibitory effects of aqueous extracts of different parts of Bidens pilosa L. var radiata on some vegetable crops. Bull. Pure Appl. Sci. 2013, 32, 11-20.

37. Mahmoud, A.; Singh, S.D.; Muralikrishna, K.S. Allelopathy in jatropha plantation: Effects on seed germination, growth and yield of wheat in north-west India. Agric. Ecosyst. Environ. 2016, 231, 240-245. [CrossRef]

38. Aliskan, I.K.; Terzi, I. Allelopathic effects of walnut leaf extracts and juglone on seed germination and seedling growth. J. Hortic. Sci. Biotechnol. 2001, 76, 436-440. [CrossRef]

39. Thomaszewishi, M.; Thimann, K.V. Interaction of phenolic acids, metallic Ions and chelating agents on auxin-induced growth. Plant Physiol. 1966, 41, 1443-1454. [CrossRef]

40. Yu, J.Q.; Matsui, Y. Effects of root exudates of cucumber (Cucumis sativus) and allelochemicals on Ion uptake by cucumber seedlings. J. Chem. Ecol. 1997, 23, 817-827. [CrossRef]

41. Zeng, R.S.; Luo, S.M.; Shi, Y.H.; Shi, M.B.; Tu, C.Y. Physiological and biochemical mechanism of allelopathy of Secalonic acid F on higher plants. Agron. J. 2001, 93, 72-79. [CrossRef]

42. Roshchina, V.V.; Roshchina, V.D. The Excretory Function Higher Plants; Springer: New York, NY, USA, 1993; pp. 213-215.

43. Huang, Y.; Bai, Y.; Wang, Y.; Kong, H. Allelopathic effects of the extracts from an invasive species Solidago canadensis L. on Microcystis aeruginosa. Lett. Appl. Microbiol. 2013, 57, 451-458. [CrossRef] [PubMed]

44. Klaudia, B. Morphological changes in two tobacco and petunia cultivars under exposure to tropospheric ozone. Acta Biol. Crac. Ser. Bot. 2013, 55, 1-9. [CrossRef]

45. Mallik, A.U.; Biswas, S.R.; Collier, L.C.S. Belowground interactions between Kalmia angustifolia and Picea mariana: Roles of competition, root exudates and ectomycorrhizal association. Plant Soil 2016, 403, 471-483. [CrossRef]

46. Maxwell, K.; Johnson, G.N. Chlorophyll fluorescence-a practical guide. J. Exp. Bot. 2000, 345, 659-668. [CrossRef]

47. Tommasion, E.; Griffa, S.; Grunberg, K.A.; Ribotta, A.N.; Colomba, E.L.; Carloni, E.; Quiroga, M.P.; Luna, C. Malondialdehyde content as a potential biochemical indicator of tolerant Cenchrus ciliaris L. genotypes under heat stress treatment. Grass Forage Sci. 2012, 67, 456-459. [CrossRef]

48. Einhellig, F.A. Mechanism of Action of Allelochemicals in Allelopathy; ACS Publications: Washington, DC, USA, 1995; Volume 582, pp. 96-116.

(C) 2018 by the authors. Licensee MDPI, Basel, Switzerland. This article is an open access article distributed under the terms and conditions of the Creative Commons Attribution (CC BY) license (http:/ / creativecommons.org/licenses/by/4.0/). 